\title{
SAÚDE SEXUAL DE HOMENS DE 25 A 59 ANOS NA ATENÇÃO PRIMÁRIA À SAÚDE
}

\author{
SEXUAL HEALTH OF MEN FROM 25 TO 59 YEARS IN PRIMARY \\ HEALTH CARE
}

\section{SALUD SEXUAL DE HOMBRES DE 25 A 59 AÑOS EN LA ATENCIÓN PRIMARIA A LA SALUD}

\author{
Thais Cordeiro Parauta* \\ Jozeane Seabra Da Silva** \\ Giovanna Thayla Caetano De Lima** \\ Mariana Da Costa Conde**** \\ Bruna Lopes SaLdanha***** \\ Adriana Lemos******
}

\begin{abstract}
RESUMO
Objetivo: Conhecer as demandas do campo da saúde sexual de homens através do relato dos profissionais de saúde da Atençáo Primária e identificar que ações são realizadas e direcionadas aos homens para atender suas demandas. Material e Método: Pesquisa descritiva com abordagem qualitativa cuja produção dos dados foi realizada com base em um roteiro semiestruturado aplicado a 17 profissionais referente à caracterização dos entrevistados, questôes de conhecimentos gerais sobre saúde sexual e questóes específicas sobre as demandas no campo da sexualidade dos homens dentro da faixa etária de 25 a 59 anos. O estudo foi realizado na Unidade de Estratégia Saúde da Família localizada na zona Sul do Rio de Janeiro, durante o período de Dezembro de 2016 a Janeiro de 2017. Utilizou-se a técnica de amostragem por saturação teórica para definir o total de entrevistados. Para o tratamento dos dados foi utilizada a análise de conteúdo por meio da técnica temática categorial, sistematizada pelo modelo de Oliveira. Resultados: As principais demandas dos homens referemse ao tratamento de infecçóes sexualmente transmissíveis (IST), impotência e a exames/procedimentos. As ações individuais constituem-se principalmente de consultas, orientações e solicitação de exames. Já em ações coletivas, a maioria é voltada para grupos que não são fechados aos homens. Conclusão: Por fim, a abordagem à sexualidade masculina ainda está reduzida aos termos das IST, medicalização e da ereção, sendo a sexualidade vista num padrão biomédico.
\end{abstract}

Palavras-chave: Saúde do homem; Sexualidade; Atenção primária à saúde.

*Enfermeira, ex-bolsista PIBIC, Universidade Federal do Estado do Rio de Janeiro, Rio de Janeiro, Brasil. Email: tcordeirop@hotmail.com **Acadêmica de enfermagem, Universidade Federal do Estado do Rio de Janeiro, Rio de Janeiro, Brasil. Email: jozeane.seabra@hotmail.com. Autor correspondente.

***Acadêmica de enfermagem, Universidade Federal do Estado do Rio de Janeiro, Rio de Janeiro, Brasil. Email: giovannathayla@gmail.com

****Enfermeira, Universidade Federal do Estado do Rio de Janeiro, Rio de Janeiro, Brasil. Email: mari.costa.conde@gmail.com

*****Enfermeira Obstetra, Universidade Federal do Estado do Rio de Janeiro, Rio de Janeiro, Brasil. Email: brunalsaldanha@gmail.com

******Enfermeira, Universidade Federal do Estado do Rio de Janeiro, Rio de Janeiro, Brasil. Email: adrianalemos@unirio.br 


\section{ABSTRACT}

Objective: To know the demands of the field of men's sexual health using reports of health professionals in Primary Care and to identify which actions are directed to meet their demands. Material and Method: Descriptive research with a qualitative approach, carried out between December 2016 and January 2017 at the Family Health Strategy Unit, located in the south of Rio de Janeiro, in which 17 health professionals (nurses and physicians) participated. Based on a semi-structured interview, questions related to general knowledge about sexual health and specific questions about the demands in the field of sexuality of men between 25 to 59 years were answered. The sample was defined through theoretical saturation and the content analysis was carried out using thematic categories according to Oliveira's model. Results: The main demands of men refer to the treatment of sexually transmitted infections (STIs), impotence and examinations/procedures. The individual actions are mainly consultations, guidelines and request for medical examinations. Collective actions are mainly directed to groups that are not exclusive to men. Conclusion: The way male sexuality is approached has a biomedical pattern, i.e., it is reduced to STIs, medicalization and erection.

Key words: Men's health; Sexuality; Primary health care.

\section{RESUMEN}

Objetivo: Conocer las demandas del campo de la salud sexual de hombres a través del relato de los profesionales de salud de la Atención Primaria e identificar qué acciones se realizan dirigidas a los hombres, para atender sus demandas. Material y Método: Investigación descriptiva con enfoque cualitativo cuya producción de datos se realizó a 17 profesionales en base a una encuesta semiestructurada para la caracterización de los entrevistados, con preguntas de conocimiento general sobre salud sexual y preguntas específicas sobre las demandas en el campo de la sexualidad masculina, en edades de 25 a 59 años. El estudio se realizó en la Unidad de Estrategia de Salud Familiar ubicada en el sur de Río de Janeiro, desde diciembre de 2016 hasta enero de 2017. La técnica de muestreo de saturación teórica se utilizó para definir el número total de encuestados. Para el tratamiento de los datos, se utilizó el análisis de contenido mediante la técnica temática categórica, sistematizada por el modelo de Oliveira. Resultados: Las principales demandas de los hombres se refieren al tratamiento de infecciones sexualmente transmisibles (IST), impotencia y exámenes/procedimientos. Las acciones individuales se constituyen principalmente de consultas, orientaciones y solicitud de exámenes. Ya en acciones colectivas, la mayoría están dirigidas a grupos que no están cerrados a los hombres. Conclusión: Por último, el abordaje a la sexualidad masculina todavía está reducida a los términos de las IST, medicalización y de la erección, siendo la sexualidad vista en un patrón biomédico.

Palabras clave: Salud del hombre; Sexualidad; Atención Primaria de Salud.

Fecha recepção: 17/01/2019

Fecha aceptação: 06/05/2019

\section{INTRODUÇÃO}

Os homens possuem baixa procura por assistência em saúde em razão de sua autopercepção de necessidades de cuidados e/ou pela noçáo de que esta é uma tarefa do feminino. Reis e Pereira ${ }^{(1)}$ apontam que uma das razóes da baixa adesão dos homens aos serviços de saúde, está relacionada às barreiras socioculturais e institucionais. A estrutura de identidade de gênero, ao constituir a noção de invulnerabilidade, força e virilidade como um valor da própria cultura, dificulta o reconhecimento dos homens em relação às suas necessidades de cuidado à saúde, somando com a imagem que têm dos serviços como um espaço feminino por excelência, destinado às mulheres, crianças, adolescentes e idosos tornando-os, assim, vulneráveis a uma série de situaçóes que poderiam ser evitáveis ${ }^{(1-2)}$. 
A construção da identidade masculina está relacionada ao desempenho sexual, em que os homens são orientados a assumir comportamentos voltados a performances intimistas devendo, para isso, ser silenciosos ou discretos quando falam a respeito de suas dificuldades ${ }^{(3)}$. De forma geral, as características dos homens que procuram os serviços de saúde opóem-se às características das mulheres. Os homens, por procurarem o serviço quando já estão com a doença instalada, valorizam as práticas curativas, não reconhecendo a importância e a necessidade das açóes de prevenção ou promoçáo da saúde ${ }^{(4)}$. É consenso que o homem adulto limita sua procura pelo serviço de saúde apenas em situações extremas, mas é possível que esta procura seja ainda menor ao se tratar de questáo de sua sexualidade ${ }^{(5)}$. Dados analisados pelo Ministério da Saúde do Brasil ${ }^{(6)}$ informam que os homens adultos, comparados com as mulheres, possuem maior morbimortalidade, principalmente por causas externas. Sendo essa morbimortalidade relacionada ao padrão de comportamento dessa população em não procurar os serviços de saúde ou procurar em situações extremas. Os mais jovens também podem ter um padrão diferenciado de autocuidado e busca pelos serviços de saúde, assim como os homens idosos, o que merece uma investigação posterior. Entendemos que homens, assim como as mulheres, não é uma categoria única, suas vivências são marcadas por questôes geracionais, raciais e sócioculturais, e que traz maiores desafios para a atenção à saúde.

Discutir sobre sexualidade é uma tarefa árdua, por ser um assunto pouco abordado e que muitos consideram um tabu, incluindo os próprios homens e boa parte dos profissionais de saúde ${ }^{(7)}$. Isto se dá porque a sexualidade está permeada por diversas questôes como as religiosas, que punem aqueles que buscam o sexo como fonte de prazer, tornando ainda mais difícil a discussão desse assunto ${ }^{(8)}$. A sexualidade muitas vezes não é vista como um componente importante para a qualidade de vida das pessoas.

Em 2012 o Instituto Lado a Lado pela Vida lançou o movimento "Novembro Azul", que foi voltada, inicialmente, à prevenção do câncer de próstata $^{(9)}$. Atualmente, o Ministério da Saúde, em parceria com o Instituto Lado a Lado pela Vida e a Sociedade Brasileira de Urologia, optou por enfocar no Novembro Azul a saúde integral do homem, em todas as suas especificidades, e não somente no câncer de próstata ${ }^{(9)}$. Em agosto de 2008 foi criada a Política Nacional de Atenção Integral à Saúde do Homem (PNAISH) ${ }^{(10)}$, objetivando orientar as açóes e serviços de saúde para a população masculina, primando pela humanização da atenção. Porém, para garantir a qualidade da assistência e alcançar os objetivos dessa política, é necessário que ela seja implementada efetivamente ${ }^{(11)}$ e a enfermagem tem papel fundamental nessa implementação, pois em sua prática na atenção primária, os homens participam dos grupos de planejamento reprodutivo, quando demandam por vasectomia, o quando nos grupos com pessoas com diabete e hipertensão, por exemplo, há aspectos sobre a sexualidade a serem tratados. A terceira idade também é citada como sujeitos de direitos sexuais, reconhecendo que o exercício da sexualidade não é necessariamente interrompido com o avanço da idade $^{(10)}$.

Os primeiros estudos sobre a saúde de homens surgiram nos anos 70 do século passado, nos Estados Unidos, e a PNAISH é uma política pioneira no cenário mundial, sendo a primeira política pública de saúde especifica para os homens na América Latina e a segunda no continente americano, depois do Canadá, sendo possível verificar que políticas públicas, pautadas na perspectiva de gênero, foram sendo incentivadas desde a Conferência Internacional de Desenvolvimento do Cairo, em $1994^{(12)}$.

No que se refere ao planejamento reprodutivo masculino, o Caderno de Direitos Sexuais, Direitos Reprodutivos e Métodos Anticoncepcionais elaborados pelo Ministério da Saúde do Brasil, em 2009, aborda os métodos anticoncepcionais e apresenta a camisinha masculina e a vasectomia ${ }^{(13)}$. Em relação às politicas, as suas açóes são ofertadas também na atenção primária a saúde (APS), que é a porta de entrada dos usuários no sistema de saúde brasileiro. É o primeiro nível de atenção que está relacionado à promoção e a proteção da saúde, a prevenção de agravos, a reabilitação a manutenção da saúde, entre outros ${ }^{(6)}$.

Considerando a problemática exposta, os objetivos deste estudo foram: Conhecer as demandas do campo da saúde sexual de homens, por meio de relatos dos profissionais de saúde da atenção primária em saúde; e identificar que ações são realizadas por esses profissionais, para atender as demandas desses homens. 
De acordo com Iunes ${ }^{(14)}$, definimos demanda como sendo a quantidade de serviço que um indivíduo consome em determino local, ou seja, o homem procura a Unidade Básica de Saúde (USB) por uma demanda de saúde dele. E o papel do enfermeiro é fundamental nessas açóes. Segundo Matumoto ${ }^{(15)}$, compreende-se a prática do enfermeiro na APS brasileira como prática social, ou seja, uma prática organizada a partir das necessidades em saúde da populaçáo naquele momento, sendo portanto dinâmica. Dessa forma, é necessária a realização dos diagnósticos situacionais de tempos em tempos para poder identificar as mudanças.

\section{MATERIAL E MÉTODO}

Tipo de estudo: Trata-se de pesquisa de caráter descritivo ${ }^{(16)}$, tem como objetivo primordial a descrição das características de determinada população ou fenômeno, o estabelecimento de relações entre variáveis, com abordagem qualitativa por se fundamentar na compreensão das opiniôes, dos significados, dos valores e crenças atribuídos pelos informantes sobre o fenômeno analisado ${ }^{(17)}$.

Coleta de dados: A produção dos dados foi realizada com base em um roteiro de entrevista semiestruturado, sendo a primeira parte do roteiro referente à caracterização dos profissionais entrevistados; na segunda parte, questóes de conhecimentos gerais sobre saúde sexual; e na última parte, as questóes específicas sobre as demandas no campo da sexualidade dos homens dentro da faixa etária de 25 a 59 anos. Vale ressaltar que a escolha da faixa etária deu-se devido a PNAISH ${ }^{(10)}$ apresentar essa faixa como sendo correspondente a $41,3 \%$ da populaçáo masculina ou a $20 \%$ do total da população do Brasil.

Participantes: $\mathrm{O}$ estudo foi realizado na Unidade de Estratégia Saúde da Família localizada na zona Sul do Rio de Janeiro, tendo como participantes enfermeiros e médicos da Unidade, que não tinham nenhum tipo de relacionamento com as entrevistadoras, evitando assim possíveis conflitos de interesse. Os critérios de inclusão foram profissionais de saúde que atuam na Unidade há mais de seis meses e que realizam consultas com homens adultos. As entrevistas foram realizadas por três acadêmicas de enfermagem da Universidade
Federal do Estado do Rio de Janeiro, durante o período de Dezembro de 2016 a Janeiro de 2017; foram gravadas em aparelho de áudio digital com autorização prévia dos participantes, sendo posteriormente transcritas na íntegra a fim de garantir a fidedignidade das respostas e evitar a perda de qualquer informação relevante. Com o intuito de respaldar a finalização da coleta de dados, utilizou-se a técnica de amostragem por saturação teórica ${ }^{(18)}$ para definir o total de entrevistados. Para o tratamento dos dados foi utilizada a análise de conteúdo $^{(19)}$ por meio da técnica temática categorial, sistematizada pelo modelo de Oliveira ${ }^{(20)}$. Após a realização da leitura flutuante, foi feito o levantamento das hipóteses provisórias do conteúdo analisado e, em seguida, iniciada a análise temática com a escolha das Unidades de Registro (UR) por meio de frases. Assim, posteriormente ao levantamento das UR, foi realizado o levantamento do tema ou Unidade de Significação (US). A análise categorial iniciou-se a partir da determinaçáo e quantificação dos temas encontrados, que foram agrupados e originaram as categoriais apresentadas, consideradas pertinentes, segundo a sua frequência de aparição ${ }^{(20)}$.

Após receberem todos os esclarecimentos pertinentes ao estudo foi ainda assegurada a confidencialidade dos dados, bem como o respeito ao anonimato dos sujeitos envolvidos. Estes, após todos os esclarecimentos, assinaram um Termo de Consentimento Livre e Esclarecido - TCLE, e os que aceitaram participar do estudo receberam um codinome com a letra "PS" (Profissional de Saúde) maiúscula seguida de números (PS1, PS2, PS3...), de acordo com a ordem de realizaçáo das entrevistas. Ressalta-se que a fim de garantir o cumprimento das questóes éticas, o estudo foi aprovado pelos Comitês de Ética em Pesquisa/CEP-UNIRIO e SMS/RJ, com Pareceres no 541.462 e no 527.958, respectivamente, considerando-se o que prevê a Resolução no 466/12 do Conselho Nacional da Saúde, que estabelece normas para a pesquisa com animais e seres humanos ${ }^{(21)}$.

\section{RESULTADOS}

Neste estudo foram encontradas 143 UR, organizadas em 17 US e que originaram quatro categorias explicitadas a seguir: 1) Prática Sexual: 
o poder da impotência; 2) Exame/Procedimento;

3) Ações dos profissionais; 4) Habilidade de comunicação verbal/vínculo. As categorias foram agrupadas em dois blocos analíticos: Demandas do campo da saúde sexual dos homens e Açóes dos profissionais.

Caracterizaçáo dos participantes: Dos 17 participantes, 9 eram enfermeiros e 8 médicos, 76\% do sexo feminino, $71 \%$ com idades entre 24 e 34 anos, $53 \%$ consideraram-se brancos, $41 \%$ disseram ser católicos e 53\% praticantes da religião. Quanto à influência da religião na prática profissional, $82 \%$ negaram-na. Quanto ao tempo de formação, 59\% dos profissionais tinham entre um e cinco anos de formação e quanto à formação em pós-graduação, $82 \%$ afirmaram possuir alguma especialização (Tabela 1).
Neste estudo, não foi questionado se os profissionais tiveram em sua graduação, pósgraduação ou capacitação profissional, aulas sobre gênero, masculinidade ou até mesmo saúde da população masculina, temas fundamentais para os saberes e práticas na atenção à saúde. Ainda que o grupo de participantes fosse composto de duas categorias profissionais, e homens e mulheres no corpus de análise, não se identificaram elementos substantivos que os diferenciassem, portanto nossa discussão é apresentada de forma geral.

\section{Demandas do campo da saúde sexual dos homens:}

1) Prática Sexual: o poder da impotência: Nesta categoria observa-se o relato dos entrevistados em que, de acordo com suas vivencias, as demandas que a maioria dos homens traz para as consultas,

Tabela 1. Caracterização dos participantes da pesquisa.

\begin{tabular}{|c|c|c|c|}
\hline Características & & Fr & $\%$ \\
\hline \multirow[t]{3}{*}{ Cor/Raça } & Negros & 2 & 12 \\
\hline & Pardos & 2 & 12 \\
\hline & Brancos & 6 & 35 \\
\hline \multirow[t]{2}{*}{ Sexo } & Feminino & 13 & 76 \\
\hline & Masculino & 4 & 24 \\
\hline \multirow[t]{2}{*}{ Idade } & 24 e 34 anos & 12 & 71 \\
\hline & 37 e 54 anos & 5 & 29 \\
\hline \multirow[t]{6}{*}{ Religião } & Católicos & 7 & 41 \\
\hline & Espírita & 2 & 12 \\
\hline & Evangélico & 1 & 6 \\
\hline & Cristão & 1 & 6 \\
\hline & Budista & 1 & 6 \\
\hline & Ateu & 5 & 29 \\
\hline \multirow[t]{3}{*}{ Praticante da religião } & Sim & 9 & 53 \\
\hline & Não & 5 & 29 \\
\hline & Mais ou menos & 3 & 18 \\
\hline \multirow[t]{2}{*}{ Influencia da religiáo na práçtica profissional } & Sim & 3 & 18 \\
\hline & Não & 14 & 82 \\
\hline \multirow[t]{3}{*}{ Tempo de formação } & $1-5$ anos & 10 & 59 \\
\hline & $6-12$ anos & 6 & 35 \\
\hline & Acima de 12 & 1 & 6 \\
\hline \multirow[t]{2}{*}{ Formação em pós graduação } & Sim & 14 & 82 \\
\hline & Não & 3 & 18 \\
\hline TOTAL & & 17 & 100 \\
\hline
\end{tabular}


estão relacionadas ao tratamento de infecçóes sexualmente transmissíveis (IST) ou questóes referentes à disfunção erétil. Percebeu-se, através dos profissionais, que a procura por assistência é pós-exposição, ou seja, depois da relaçáo sexual sem preservativo. Eles buscam a Unidade para verificar se houve contágio e se tiver acontecido, realizar o tratamento adequado:

Os homens procuram mais quando eles fazem alguma besteira. [...] quando eles se expóem a riscos [...] apresentam alguma sintomatologia de DST [...]. Mas para orientação, o homem é mais fechado. Ele não vem procurar uma orientação, ele vem pra procurar uma solução" (PS 05 - Enfermeiro).

Podemos verificar a alta vulnerabilidade que os homens adultos possuem devido essa exposição às doenças. É possível verificar também que a população masculina deixa em segundo plano as práticas preventivas que envolvem as açóes referentes à promoção e proteção em saúde e também o diagnóstico, tratamento precoce e reabilitação quando há uma doença instalada, sendo o objetivo dessas últimas, a limitação dos danos.

Em relação a pouca procura e à necessidade de cuidado dos homens, pode-se perceber nas falas abaixo que, quando o homem procura o serviço de saúde para levar alguma demanda, ele é mais pontual e objetivo, sendo uma busca tardia pelos serviços, com a doença já instalada e com a sintomatologia aparente, novamente desvalorizando as práticas preventivas, dando maior ênfase às praticas curativas:

"Eles é que vem até a unidade com uma queixa e a gente descobre que [...] enfim [...] quando é clinico assim a gente vê o que é [...] gonorreia, é isso, aquilo [...] dai a gente pede o teste rápido e descobre que está com sifilis, está com HIV [...] normalmente eles procuram a gente porque já estão por um tempinho com algum problema, entendeu?! Nunca é tipo ah, começou semana passada, é sempre ah, eu já estou há seis meses com esse problema" (PS 03 - Enfermeiro).

"É, o homem na verdade, questáo sexual ele vem bem pontualmente já falando sobre o quadro, mesmo que seja uma DST [...]. Ele demora a vir, não tem essa frequência, não tem o [...] espera o quadro evoluir muito para poder vir falar com a gente. Não procura logo no inicio, diferente da mulher" (PS 13 - Médico).
2) Exames e/ou procedimentos: $O$ outro tipo de demanda que os homens trazem é em relação a exames, como: teste rápido, espermograma, dosagem sérica do Antígeno Prostático específico (PSA) e procedimentos, como vasectomia. Somente dois entrevistados citaram como demanda o exame de PSA:

"Eles só procuram quando eles têm algum problema. Eles normalmente procuram a gente para fazer PSA" (PS 07 - Enfermeira).

Conceitos como disfunção erétil, distúrbio androgênicodoenvelhecimento masculino(DAEM) e reposição hormonal masculina, frequentam cada vez mais a mídia. Ao buscar esclarecimento sobre a sexualidade masculina em relação aos cuidados com a saúde do homem, foi possível verificar, na fala dos profissionais, expressóes referentes ao medo de ter a doença, a busca tardia pelo serviço de saúde e a procura por realizar os exames, não como uma ação preventiva e sim como uma ação diagnóstica pósexposição. Isso permite que as vulnerabilidades aos agravos desses homens sejam muito maiores.

3) Açóes dos profissionais: Os profissionais informaram que essas açóes voltadas para a sexualidade em relação aos homens, em sua maioria, são individuais e constituem-se principalmente nas consultas, ocasião em que são feitas orientaçóes e solicitação de exames. É possível perceber a inexistência de açóes visando à promoção da saúde dos homens:

"A gente, quando o homem trás uma queixa masculina, assim, a gente sempre entra na abordagem dos testes rápidos, de fazer solicitação dos testes rápidos, entra nos métodos, camisinha, de barreira mesmo. E basicamente é isso" (PS 10 - Médico).

$\mathrm{Na}$ fala acima, assim como nas falas dos outros profissionais (enfermeiros) é possível perceber que não existe um grupo ou ação voltada para a demanda desses homens, somente orientação, o que pelas falas dos entrevistados, não está surtindo efeito. Mesmo assim, não se faz nada, ainda que seja um direito deles a integralidade da atenção à saúde.

A partir da análise das entrevistas, caracterizouse que a maiorias das açóes são voltadas ao grupo de planejamento familiar ou da gestante, onde 
é abordada a saúde sexual e reprodutiva, porém, muito mais direcionada às mulheres do que aos homens. Poucos dentre os discursos analisados, referem-se à tentativa de desenvolverem estratégias que tragam os homens aos serviços de saúde, como a sala de espera e açóes do Novembro Azul. Inferimos que os profissionais não tem tido oportunidades de capacitaçáo direcionadas para atenção à saúde do homem, para uma busca ativa pelos homens aos serviços e também organização de açôes/atividades que os interessam e acolham.

\section{4) Habilidade de comunicaçáa verbal/Vínculo:}

Apenas um entrevistado referiu-se à habilidade de comunicação verbal como uma açấo importante para atender as demandas desses homens:

"Eu tento sempre abordar um pouco da forma que a pessoa fala, tipo a nomenclatura que a pessoa usa, eu uso de volta com ela pra ela se sentir um pouco mais a vontade" (PS 11 - Médica).

Outro aspecto relevante, no entanto, referido por apenas três entrevistados, foi o vínculo como um importante gesto para que o usuário consiga ficar à vontade para falar a respeito de seus problemas ou dúvidas relacionados à saúde sexual e dar continuidade ao tratamento:

"Aproximar e criar vinculo e que ele venha dar continuidade no tratamento se necessário [...]. Tem que criar esse contexto na equipe, consolidar o paciente na equipe, a gente estar presente e criar o vinculo" (PS 04 - Enfermeira).

Os entrevistados relataram que os homens têm dificuldades em abordar demandas sexuais/ reprodutivas e também em relação à vergonha que o homem sente em ser atendido por uma profissional mulher.

Vale ressaltar que apenas os trechos das falas dos participantes mais relevantes para o estudo foram adicionados ao manuscrito.

\section{DISCUSSÃO}

O homem adulto possui uma especificidade, que é esse distanciamento do serviço de saúde devido a muitas questóes, sendo uma delas a identidade de gênero, gerando a ideia de invulnerabilidade ${ }^{(1-2)}$. E quando falamos de demandas sexuais essa busca tende a diminuir devido ao forte tabu que esse tema é para grande parte da populaçāo(5). A disfunção erétil e tratamento de IST são temas presentes quando se fala de sexualidade masculina, o que está de acordo com Arduini e Santo ${ }^{(5)}$ quando referem que saúde sexual dos homens ainda é pautada nas infecções sexualmente transmissíveis e na ereção peniana, o que reforça a ideia de que o homem ainda está centrado no modelo biomédico e de que o pênis ereto é a representação da sua masculinidade.

Quando se buscam estudos sobre a sexualidade nos grupos de idade adulta, eles são escassos. $\mathrm{E}$ o processo de medicalização é fortemente percebido quando a sexualidade está atrelada a medicamentos que visam curar determinadas doenças que podem afetá-la. Nestes termos, a sexualidade masculina encontra-se centrada no pênis e a pela simplicidade do seu funcionamento, ou seja, é concebida como atividade estritamente orgânica ${ }^{(22)}$.

Além dos homens apresentarem maior predisposição e vulnerabilidade para adquirir doenças relacionadas à sexualidade, eles também desvalorizam as práticas de prevenção e de cuidados com a saúde. De certa forma porque os serviços também pouco abordam essas questóes, sobretudo na perspectiva masculina, devido à escassa discussão na própria formaçấo profissional. Mesmo assim, essas práticas são desenvolvidas pelo Enfermeiro e alavancam mudanças no modelo de assistência à saúde do SUS (23).

Considera-se importante refletir sobre as dificuldades e resistências dos homens a aderirem aos serviços de saúde e o desafio que isso se torna para a Enfermagem na Atenção Básica. A Enfermagem tem responsabilidade nesse contexto quando verificamos a baixa produção cientifica relacionada a saúde do homem e em relaçáo a baixa procura por atendimento. Visto o papel fundamental do Enfermeiro em açóes de promoção em saúde com homens sobre a importância do cuidado com a sua saúde. Essa é uma problemática que a profissão deve ajudar a resolver ou, pelo menos, minimizar ${ }^{(4)}$.

Alguns pesquisadores relatam que os homens acreditam que as mulheres adoecem mais elevando, assim, a vulnerabilidade deles aos agravos, em consequência da não procura pelos serviços de saúde ${ }^{(4,24)}$. Dessa forma, as construçôes de masculinidade afeta profundamente o cuidado em 
saúde. Além disso, demandar cuidados de saúde é algo que desmerece sujeitos criados para prover e ser viril. Portanto, admite-se que a demanda por assistência não seja de caráter preventivo, e sim de caráter curativo ${ }^{(25)}$, como vimos nos relatos sobre demanda para exames diagnóstico.

O homem quando vai até o serviço de saúde, busca um atendimento rápido e resolutivo, o que pode significar dificuldade em relação ao vínculo que se necessita estabelecer para tratar questôes referentes à saúde sexual ${ }^{(26)}$. Devido aos comportamentos de risco desses homens, faz-se necessário um questionamento acerca da necessidade de se abordar a sexualidade nas escolas realizando educação em saúde com Enfermeiros, por ser o local mais propício para começar a desenvolver uma prática educacional em sexualidade, pois, esse assunto, além de pouco debatido na área da saúde, costuma ser abordado quase que exclusivamente nos termos da lógica da doença ${ }^{(27)}$.

Em relação ao rastreamento do câncer de próstata, o INCA não indica essa prática, pois os danos superam os possíveis benefícios. O Toque retal e o PSA são indicados quando existam os sinais de alerta. Assim é preciso que os profissionais tenham conhecimento dos protocolos para que estejam atentos a esses sinais e que para realizar o encaminhamento para a investigação diagnóstica para a realização dos exames ${ }^{(28)}$. Vale ressaltar que o toque retal é uma prática utilizada para avaliação da presença de nódulos e do tamanho desses. Já o PSA, é um marcador biológico de doenças prostáticas ${ }^{(29)}$. De acordo com alguns estudos, os riscos de neoplasias de próstata são deixados em segundo plano devido a sociedade possuir, ainda, uma visão "machista" junto com a vergonha de se expor, criando uma realidade que dificulta a realização de práticas que ameacem a masculinidade, contribuindo para uma forte resistência dos homens na procura dos serviços de saúde ${ }^{(26,30-31)}$.

Os profissionais participantes da pesquisa trouxeram em suas discussóes, uma deficiência de conhecimentos acerca da temática em estudo, haja vista a pouca demanda do público masculino na ESF e a consequente ausência de açóes voltadas para as suas necessidades sexuais e reprodutivas. Enfermeiros demonstram que conhecem a política, porém, não desenvolvem açôes que estimulem a presença do homem nas unidades ${ }^{(32)}$. Dessa forma, cabe questionar se a ausência dos homens nos serviços de saúde está associada à invisibilidade não do sujeito, mas sim de políticas de saúde e açóes que tratem o homem como protagonista de suas açóes ${ }^{(26)}$, bem como da pouca ou nenhuma discussão sobre masculinidade e/ou saúde do homem no âmbito da formação profissional e da educação permanente nos serviços de saúde.

As ações realizadas pelos profissionais são individuais, encontram-se centradas nas consultas e tomam, como referência, a percepção desses entrevistados que, adotando como modelo de atenção à saúde atual vigente essas mesmas percepçóes, afirmam que esses modelos se mantêm assistencialistas e pouco capazes de responder às necessidades da população masculina. São modelos curativistas, operados por profissionais muitas vezes despreparados para atuarem com o respeito devido aos direitos do usuário e suas necessidades e com a qualidade necessária. São centrados no profissional médico, priorizam mais a doença, gerando expectativa de que a única forma de resolver os problemas de saúde seja tratando a doença por meio de medicamentos ${ }^{(2)}$.

Ao tentarem desenvolver atividades para o público masculino, os profissionais não obtiveram a presença desse grupo, o que demonstra a baixa adesão masculina nos serviços. Assim, verifica-se a necessidade de estratégias dentro e fora da unidade de saúde sobre promoção e prevenção de doenças e agravos, desde a adolescência até a terceira idade, para desmistificar a sexualidade como um tabu ${ }^{(11)}$.

A habilidade de comunicação verbal e o vínculo são importantes para se tratar questões relacionadas à sexualidade. Por exemplo, grupo de homens de uma Unidade de Saúde da Família, aonde a partir de metodologias ativas os homens tratavam de suas questóes, interagindo entre si, rompendo com medos, preocupaçóes e, também, preconceitos ${ }^{(33)}$.

\section{CONCLUSÃO}

As demandas em saúde sexual apresentadas pelos usuários, na visão dos profissionais, recebem pouca atenção já que não há nenhuma ação específica para esses homens, além da consulta, da orientação, dos exames e do teste rápido. $\mathrm{E}$ as principais açōes, tanto individuais como coletivas, são basicamente orientaçóes em consulta ou em grupos onde o homem pode participar, visto que não é encontrado 
na unidade, grupos específicos para os homens. Porém, não se sabe ao certo a qualidade dessas ações e como elas são abordadas, principalmente nos grupos, já que não são direcionadas aos homens.

Com boa comunicação verbal e o mínimo de vínculo se consegue construir laços de confiança e segurança para que o homem sinta-se acolhido e seguro para falar sobre suas verdadeiras demandas. Durante o estudo, ficou clara a importância dos programas de capacitação para os profissionais de saúde, para que se tenha uma assistência

\section{REFERÊNCIAS}

1. Reis A, Pereira A. Saúde de homens: conceitos e práticas de cuidados. $1^{a}$ ed. Rio de Janeiro: Águia Dourada; 2017. 688 p.

2. Silva AS, Fracolli A. Avaliação da Estratégia Saúde da Família: perspectiva dos usuários em Minas Gerais, Brasil. Saúde debate. 2014; 38(103): 692705.

3. Amorim RF, Catrib AMF, Jorge MSB. Olhares da saúde coletiva sobre o corpo. 1. ed. Fortaleza: Universidade de Fortaleza, EdUECE; 2011. 303 p.

4. Albuquerque GA, Leite MF, Belém JM, Nunes JFC, Oliveira MA, Adami F. The man in primary healthcare: perceptions of nurses about the implications of gender in health. Esc Anna Nery. 2014; 18(4): 607-614.

5. Arduini JB, Santos AS. A percepção do homem idoso sobre sexualidade e AIDS. Rev enferm UERJ [Internet]. 2013 [citado 2017 mar 10]; 21(3): 379383. Disponível em: https://www.e-publicacoes. uerj.br/index.php/enfermagemuerj/article/ view/7547/5447

6. BRASIL. Ministério da Saúde. Portaria no 2.488, de 21 de outubro de 2011. Brasília [Internet], 2011. [citado 2017 mar 15]. 37 p. Disponível em: https://www.nescon.medicina.ufmg.br/biblioteca/ imagem/3232.pdf

7. Luz ACG, Machado ALG, Felipe GF, Teixeira EM, Silva MJ, Marques MB. Sexual behavior in the elderly watched family health strategy. Rev pesqui cuid Fundam [internet]. 2015 [citado 2017 mar 15]; 7(2): 2229-40. Disponível em: https://www. researchgate.net/publication/276473665_Sexual_ behavior_in_the_elderly_watched_family_health_ strategy

8. Leite KLC. Implicaçôes da moral religiosa e dos pressupostos científicos na construção das representaçóes do corpo e da sexualidade femininos no Brasil. Cad. Pagu [Internet]. 2017 direcionada e qualificada à população masculina, numa abordagem que considere as especificidades dos ciclos vitais, de gênero, de raça e sócio culturais como determinantes do processo saúde e doença.

Por se tratar de um estudo de iniciação científica com prazo curto para seu desenvolvimento e maturação reconhecemos como limitaçóes o não aprofundamento analítico com suporte de marcos teóricos nos estudos de gênero, sexualidade e masculinidades, bem como a não inclusão de estudos de abrangência internacional.

[citado 2017 dez 02]; (49): 1-28. Disponível em: http://www.scielo.br/pdf/cpa/n49/1809-4449cpa-18094449201700490022.pdf

9. Brasil. Ministério da Saúde (Br). Instituto Lado a Lado pela vida. Brasília [Internet]. 2012 [citado 2017 abr 25]; Disponível em: http://www. ladoaladopelavida.org.br/

10. Brasil. Ministério da Saúde (Br). Política Nacional de Atenção Integral à Saúde do Homem [Internet]. Brasília 2008 [citado 2017 abr 25]; 40 p. Disponível em: http://bvsms.saude.gov.br/bvs/publicacoes/ politica_nacional_atencao_saude_homem.pdf

11. Silva NA, Silva AS, Silva ARV, Araújo TME, Rebouças CBA, Nogueira LT. Primary care assessment from a male population perspective. Rev Bras Enferm. 2018; 71(2); 236-43.

12. Martins AM, Malamut BS. Análise do discurso da Política Nacional de Atenção Integral à Saúde do Homem. Saúde e Soc [internet]. 2013 [citado 2017 nov 17]; 22(2); 429-440. Disponível em: http:// www.scielo.br/pdf/sausoc/v22n2/v22n2a14.pdf

13. Brasil. Ministério da Saúde. Direitos sexuais, direitos reprodutivos e métodos anticoncepcionais. Caderno n. 2 [Internet]. 2009 [citado 2017 abr 25]; 56 p. Disponível em: http://bvsms.saude.gov. br/bvs/publicacoes/direitos_sexuais_reprodutivos_ metodos_anticoncepcionais.pdf

14. Iunes RF. Demanda e demanda em saúde. In: Piola SF, Viana SM. Economia da saúde. Rio de Janeiro: IPEA; 1995. p. 99-123.

15. Matumoto S, Fortuna CM, Kawata LS, Mishima SM, Pereira MJB. Nurses' clinical practice in primary care: a process under construction. Rev Latino-Am Enfermagem [Internet]. 2011 [citado 2017 mar 15]; 19(1): 123-30. Disponível em: http://www.scielo.br/scielo.php?script=sci_ arttext\&pid=S0104-11692011000100017

16. Gil AC. Como elaborar Projetos de Pesquisa. $6^{a}$ ed. São Paulo: Atlas; 2017. 192 p.

17. Minayo MCS. O desafio do conhecimento: 
pesquisa qualitativa em saúde. $13^{a}$ ed. Sáo Paulo: Hucitec; 2014. 408 p.

18. Fontanella BJB, Luchesi BM, Saidel MGB, Ricas J, Turato ER, Melo DG. Sampling in qualitative research: a proposal for procedures to detect theoretical saturation. Cad Saúde Pública [Internet]. 2011 [citado 2017 jan 20]; 27(2): 38994. Disponível em: http://www.scielo.br/pdf/csp/ v27n2/20.pdf

19. Bardin L. Análise de conteúdo. Ediciones 70ª São Paulo: Almedina; 2011. 229 p.

20. Oliveira DC. Análise de Conteúdo Temático Categorial: Uma Proposta de Sistematização. Rev enferm UERJ. 2008; 16(4): 569-76.

21. Brasil. Conselho Nacional de Saúde. Resolução $\mathrm{n}^{\circ}$ 466, de 12 de Dezembro de 2012 [Internet]. Brasília 2012 [citado 2017 nov 17]; Disponível em: http://www.ics.ufpa.br/arquivos/cep/Reso4662012.pdf

22. Thiago CC, Russo JA, Júnior KR. Hormones, sexuality and male aging: a study of website images. Interface (Botucatu). 2016; 20(56): 37-50.

23. Barros CT, Gontijo DT, Lyra J, Lima LS, Monteiro EMLM. If the man takes care of his own health, it will seem contradictory to the work: the relation between masculinities and health care for young men in vocational training. Saúde e Sociedade. 2018; 27(2): 423-434.

24. Queiroz TS, Rehem TCMSB, Stival MM, Funghetto SS, Lima LR, Cardoso BG et al. How do old men take care of their own health in Primary Care? Rev Bras Enferm [Internet]. 2018 [cidado 2017 nov 17]; 71(Suppl 1): 554-61. Disponível em: http://www.scielo.br/pdf/reben/v71s1/pt_00347167-reben-71-s1-0554.pdf

25. Machin R, Couto MT, Silva GSN, Schraiber LB, Gomes R, Figueiredo WS, et al. Concepções de gênero, masculinidade e cuidados em saúde: estudo com profissionais de saúde da atenção primária. Ciênc saúde coletiva. 2011; 16(11): 4503-4512.
26. Lima AP, Lini EV, Giacomazzi RB, Dellani MP, Portella MR, Doring M. Prevalence and factors associated with the performance of prostate cancer screening in the elderly: a population-based study. 2018; 21(1): 53-59.

27. Zanatta LF, Moraes SP, Freitas MJD, Brêtas JRS. Sexuality education at the itinerant school of MST: students' perceptions. Educ Pesqui. 2016; 42(2): 443-58.

28. Ministerio da Saúde. Instituto nacional de câncer José Alencar Gomes da Silva (INCA). Informativo detecção precoce: monitoramento das açóes de controle do câncer de próstata. Boletim Informativo Detecção Precoce [Internet], Rio de Janeiro 2017 [citado 2017 dez 02]. 8 p. Disponível em: http://www.saude.df.gov. br/wp-conteudo/uploads/2018/03/InformativoC\%C3\%A2ncer-de-Pr\%C3\%B3stata-2017.pdf

29. Ríos LL, Montero IRS, Moreno IG. Relación entre el marcador tumoral antígeno prostático específico y la mortalidad por cáncer de próstata. Correo Científico Médico de Holguín. 2017; 21(1): 100-11.

30. Araújo JS, Conceição VM, Silva SED, Santana ME, Vasconcelos EV, Sousa RF. The social representations of men about prostate cancer. $\mathrm{R}$ de Pesq: cuidado é fundamental Online-Bra. 2013; 5(2): 3884-93.

31. Cavalcanti JRD, Ferreira JA, Henriques AHB, Morais GSN, Trigueiro JVS, Torquato IMB. Integral Assistance to Men's Health: needs, barriers and coping strategies. Esc Anna Nery. 2014; 18(4): 628-34.

32. Araújo MG, Lima GAF, Holanda CSM, Carvalho JBL, Sales LKO. Professional opinion on the effectiveness of the National Policy of Comprehensive Health Care for Men. Esc Anna Nery. 2014; 18(4): 682-689.

33. Bacelar AYS, Coni DGL, Santos DV, Souza AR. Men in the family health unit. Rev enferm UFPE on line. 2018; 12(9): 2507-13. 